\title{
The role of weak intermolecular C-H...F interactions in supramolecular assembly: Structural investigations on 3,5- dibenzylidene-piperidin-4-one and database analysis
}

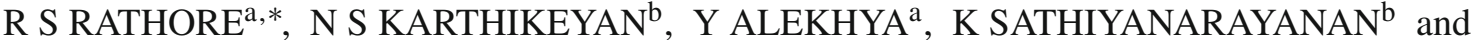 \\ P G ARAVINDAN ${ }^{c}$ \\ ${ }^{a}$ Bioinformatics Infrastructure Facility, Department of Biotechnology, School of Life Sciences, \\ University of Hyderabad, Hyderabad 500046, India \\ ${ }^{\mathrm{b}}$ Chemistry Division, School of Advanced Sciences, VIT University, Vellore 632014, India \\ ${ }^{c}$ Physics Division, School of Advanced Sciences, VIT University, Vellore 632014, India \\ e-mail: ravindranath_rathore@yahoo.com
}

MS received 23 July 2010; revised 25 March 2011; accepted 11 April 2011

\begin{abstract}
The fluorinated and non-fluorinated dibenzylidene-4-piperidones were synthesized and their structures examined using X-ray crystallography. Interestingly, the para-fluorosubstituted dibenzylidene compound, in contrast to other analogs, is characterized by $\mathrm{C}-\mathrm{H}$...F bonded one-dimensional packing motif. To evaluate the ability of hydrogen bond donors and acceptors for forming interactions, in general and competitive situation, we have defined statistical descriptors. Analysis of Cambridge Structural Database using these newly defined parameters reveals high propensity of $\mathrm{C}-\mathrm{H}$...F interactions in organic crystals. The present structural study suggests much larger role of fluorine driven intermolecular interactions that are even though weak, but possess significant ability to direct and alter the packing.
\end{abstract}

Keywords. Dibenzylidene-4-piperidones; C-H. . F interaction; fluorine interactions; weak intermolecular interactions; crystal structure; X-ray diffraction.

\section{Introduction}

Fluorine is known for its odd behaviour in non-bonded interactions. ${ }^{1}$ Fluorine atom is the most electronegative element and approximately isosteric to oxygen. While inorganic fluoride ion is the most powerful proton-acceptor (its strength of hydrogen bond is $\left.40 \mathrm{kcal} \mathrm{mol}^{-1}\right),{ }^{2}$ in staggering contrast the covalently bound fluorine is a very weak intermolecular hydrogenbonding acceptor (strength of $\mathrm{X}-\mathrm{F} . . \mathrm{H}-\mathrm{Y}$ hydrogen bond is $2-3.2 \mathrm{kcal} \mathrm{mol}^{-1}$ as compared to $5-10 \mathrm{kcal}$ $\mathrm{mol}^{-1}$ for $\mathrm{H}$... O hydrogen bond, $\mathrm{X}$ and $\mathrm{Y}$ are covalently attached atoms). ${ }^{3}$ Indeed, fluorine is considered to hardly ever form hydrogen bond. This anomalous behaviour of fluorine has been attributed to many electrostatic and steric factors such as its low polarizability and tightly contracted lone pairs. ${ }^{1-4}$

In recent years, a large number of structures containing fluorine have been reported. Upon examination, it turns out that the role assigned to fluorine as 'odd one out,' based-on analysis of $\mathrm{N}-\mathrm{H}$...F and $\mathrm{O}-\mathrm{H}$...F

\footnotetext{
${ }^{*}$ For correspondence
}

interactions in the database, ${ }^{1,2}$ is not necessarily true. Several structures having significant role of $\mathrm{C}-\mathrm{H}$...F and $\mathrm{C}-\mathrm{F} \ldots \pi$ interactions have been observed. Even though these interactions involving fluorine are much weaker than conventional N/O-H... O hydrogen bonds, their role in determining the modes of molecular packing can not be ignored. ${ }^{3,5,6}$ Indeed, there are reported examples that clearly demonstrate that weak fluorine interactions certainly alter the packing modes. ${ }^{7}$ Guru Row and co-workers have extensively studied the structural property of fluorine and they have presented several elegant examples of fluorine-directed crystal packing. ${ }^{7-10}$ In recent years, fluorine has been shown to influence non-bonded intermolecular association and ligand-receptor binding via different modes of interactions such as steroelectronic effects, as observed in many drug-receptor binding e.g., Prozac, Ciprofloxacin and Atorvastatin. ${ }^{11,12}$

It was our purpose to examine the structure directing role of fluorine in organic molecules, we have selected 3,5-dibenzylidene-piperidin-4-one class of molecules. We have recently standardized its synthetic procedure to prepare diverse set of compounds. Some of the fluo- 
<smiles>[Z]c1ccc(/C=C2\CN(Cc3ccccc3)C/C(=C\c3ccc([Z])c([X])c3)C2=O)cc1[X]</smiles>

$\mathrm{Y}=\mathrm{F}, \mathrm{Z}=\mathrm{H}(\mathbf{I})$

$\mathrm{Y}=\mathrm{H}, \mathrm{Z}=\mathrm{F}(\mathrm{II})$

$\mathrm{Y}=\mathrm{H}, \mathrm{Z}=-\mathrm{OCH}_{3}$ (III)

Figure 1. Chemical scheme.

rinated and non-fluorinated (3E,5E)-3,5-dibenzylidene4-piperidones (D4P) compounds were prepared and we could crystallize few of them. The investigated com- pounds (figure 1) are: (3E,5E)-1-benzyl-3,5-bis(3-fluorobenzylidene)piperidin-4-one (I), (3E,5E)-1-benzyl3,5-bis(4-fluorobenzylidene)piperidin-4-one (II), (3E, 5E)-1-benzyl-3,5-bis(4-methoxybenzylidene)piperidin-4one (III). The results are correlated with database survey on intermolecular interactions involving fluorine.

\section{Experimental}

\subsection{Synthesis of dibenzylidene-4-piperidones}

A mixture of 1-benzyl-4-piperidone $(0.01 \mathrm{~mol})$ and respective benzaldehyde $(0.02 \mathrm{~mol})$ was added to a warm solution of ammonium acetate $(0.01 \mathrm{~mol})$ in absolute ethanol $(15 \mathrm{ml})$. The mixture was gradually warmed on a water bath until the yellow colour changed to orange. The mixture was kept aside overnight at room temperature. Reactions were monitored with TLC for completeness. The solid obtained was separated and the crude compound was purified using silica gel column chro-

Table 1. Crystal data.

(I)

$$
\begin{aligned}
& \mathrm{C}_{26} \mathrm{H}_{21} \mathrm{~F}_{2} \mathrm{NO} \\
& 401.4 \\
& \text { yellow, block } \\
& 0.38 \times 0.28 \times 0.22
\end{aligned}
$$

Crystal size (mm)

Cell Parameters

$a(\AA)$

$b(\AA)$

$c(\AA)$

$a, \beta, y\left(^{\circ}\right)$

$V\left(\AA^{3}\right)$

Crystal system

Space group

$Z / Z^{\prime}$

$D x($ cal. $)\left(\mathrm{g} / \mathrm{cm}^{3}\right)$

$\mu\left(\mathrm{mm}^{-1}\right)$

Absorption correction

$F(000)$

Data Collection

$\theta$-range $\left(^{\circ}\right)$

Scan type

Independent reflections

Observed $[I>2 \sigma(I)]$

Refinement

Final $R\left[F^{2}>2\left(F^{2}\right)\right]$

$w R\left(F^{2}\right) \_$all

Goodness-of-fit $(S)$

$\Delta \rho_{\max }$ and $\Delta \rho_{\min }\left(\mathrm{e} \AA^{-3}\right)$

$6.6254(1)$
$10.5486(2)$
$15.7097(4)$
$103.352(1), 98.846(1), 103.249(1)$
$1014.75(4)$
Triclinic
$P \overline{1}$
$2 / 1$
1.314
0.092
multi-scan
420
$1.37-28.31$
$\phi$ and $\omega$ scans
4741
3596
0.0449
0.1526
0.941
0.224 and -0.268

$\mathrm{C}_{26} \mathrm{H}_{21} \mathrm{~F}_{2} \mathrm{NO}$

$$
401.4
$$

yellow, block

$0.32 \times 0.30 \times 0.24$

\section{$17.9058(6)$}

$6.3548(2)$

$18.6239(6)$

$90.0,96.958(1), 90.0$

2103.56(12)

Monoclinic

$P 2{ }_{1} / \mathrm{n}$

4/1

1.268

0.089

multi-scan

840

$1.49-27.41$

$\phi$ and $\omega$ scans

4781

2424

0.0496

0.1665

0.989

0.136 and -0.184
(III)

$\mathrm{C}_{28} \mathrm{H}_{27} \mathrm{NO}_{3}$

425.5

yellow, block

$0.30 \times 0.16 \times 0.16$

$12.970(5)$

$9.168(5)$

19.529(5)

90.0, 105.848(5), 90.0

2233.9(16)

Monoclinic

$P 2_{1} / \mathrm{c}$

$4 / 1$

1.265

0.082

multi-scan

904

$1.63-28.24$

$\phi$ and $\omega$ scans

5505

3563

0.0432

0.1443

1.040

0.226 and -0.196

$w=1 /\left[\sigma^{2}\left(F_{0}^{2}\right)+(a P)^{2}+b P\right]$, where $P=\left(F_{o}^{2}+2 F_{c}^{2}\right) / 3 P=\left(F_{o}^{2}+2 F_{c}^{2}\right) / 3$, parameters $a$ and $b$ are: $0.1000,0.1667(\mathbf{I})$, $0.0855,0.0000$ (II), $0.0740,0.2385$ (III), respectively. 
matography with hexane and ethyl acetate as elutant. Final yields: $89.84 \%(\mathbf{I}), 93.87 \%$ (II), and $83.20 \%$ (III); m.p. $136-140^{\circ} \mathrm{C}(\mathbf{I}), 146-150^{\circ} \mathrm{C}\left(\right.$ II), and $150-154^{\circ} \mathrm{C}$ (III). Suitable single crystals for (I-III) were grown by heating in a mixture of ethanol and tetrahydrofuran, and cooling them to room temperature. Crystals were filtered after two days.

\section{$2.2 X$-ray crystallography}

$\mathrm{X}$-ray data were collected on a single-crystal Bruker SMART CCD area-detector diffractometer. ${ }^{13}$ Empirical absorption correction was applied to the data using $S A D A B S .{ }^{13}$ The structure was solved by applying the direct phase-determination technique using SHELXS97 , and anisotropically refined by full-matrix leastsquare on $\mathrm{F}^{2}$ using SHELXL-97. ${ }^{14}$ Structure calculations were performed with WinGX suit of programs (version 1.70.01). Hydrogens were placed in the geometrically expected positions and refined with the riding options. The torsion angles for the methyl group hydrogens were set with reference to a local difference Fourier calculation. The calculated distances with hydrogen atoms are: $\mathrm{C}\left(\mathrm{sp}^{2}\right)-\mathrm{H}=0.93 \AA, \mathrm{C}$ (methyl)$\mathrm{H}=0.96 \AA$, C(methylene $)-\mathrm{H}=0.97 \AA$, and $\mathrm{U}_{\text {iso }}=$ $1.2 \mathrm{U}_{\mathrm{eq}}$ (parent), or $1.5 \mathrm{U}_{\mathrm{eq}}\left(\mathrm{C}_{\text {methyl }}\right)$. For identification of hydrogen bonds, following Jeffrey criterion, recommended by IUCr was used: H...A distance $<(\mathrm{r} 1+$ r 2 - 0.12) A and D-H. . A angle was within $100-180^{\circ}$, where $\mathrm{r} 1$ and $\mathrm{r} 2$ are the van der Waals radii of hydrogen and the acceptor atoms, respectively. Essential crystal data are listed in table 1. Crystallographic data have been deposited at Cambridge Crystallographic Data Center with entry numbers: CCDC 759527 (I), CCDC 759526 (II), and CCDC 759525 (III).

\subsection{CSD database analysis}

Search in Cambridge Structural Database (Version 5.31, updated) ${ }^{15}$ was performed using Conquest (Version 1.12). While selecting structures for their involvement in hydrogen-bonding, stringent criteria were used to assure quality extraction of data and to maximize exclusion of short van der Waals contacts. All the intramolecular contacts were discarded. Single crystal structures of organics having $R$ values less than 0.10 with their three-dimensional coordinates determined, possessing no ions, polymeric structure, disorder or errors, were extracted. Hydrogen bond distances were normalized to their neutron diffraction values. The possible intermolecular interaction was assumed, if it sat- isfied the Jeffrey criterion as described earlier. VISTA (Version 2.0) included in the CSD software suite was used for statistical analysis and calculating average values.

\section{Results and discussions}

\subsection{Molecular structure}

The stereochemistry of (I-III) is illustrated in figure 2 and supplementary figures S1 and S2 respectively. Piperidinone ring (also called piperidone; atoms N1/C2-C6) adopts characteristic sofa conformation as observed in analogous structures ${ }^{16-18,21}$ with $\mathrm{N} 1$ atom shifted out of the base plane $(\mathrm{C} 2 / \mathrm{C} 3 / \mathrm{C} 4 / \mathrm{C} 5 / \mathrm{C} 6)$ by $-0.740(1) \AA,-0.689(2) \AA$ and $-0.776(1) \AA$ in (I-III), respectively. The N1-substitent (1-benzyl group) is in equatorial position of piperidinone ring, except it occupies axial position (endo-skeleton with respect to the ring) in 3,5-bis[(E)-2-chlorobenzylidene]-1-[(R)-1-phenylethyl]piperidin-4-one. ${ }^{16}$ The C3,C5 diene moieties possess E-configuration. Details of hydrogen-bonding and short-contact geometry are described in table 2 . The conformation of 1-benzyl group is characterized by two torsion angles about N1-C7 and C7-C8 bonds. To describe the conformation, only the lowest value of the torsion angles have been used, since the corresponding aromatic proton is only able to form intra-molecular interaction. In (I-III), and previously analogous structures, ${ }^{16-18,21}$ the average torsion angles have been observed to be $|69(6)|^{\circ}$ and $|43(15)|^{\circ}$, respectively. In (I-III) the torsion angles are following: (I), $\mathrm{C} 2-\mathrm{N} 1-\mathrm{C} 7-\mathrm{C} 8=-74.15(16)^{\circ}, \mathrm{N} 1-\mathrm{C} 7-\mathrm{C} 8-\mathrm{C} 13=$ $-56.95(18)^{\circ} ;$ (II), $\mathrm{C} 2-\mathrm{N} 1-\mathrm{C} 7-\mathrm{C} 8=-62.6(2)^{\circ}$, $\mathrm{N} 1-\mathrm{C} 7-\mathrm{C} 8-\mathrm{C} 13=-49.4(3)^{\circ} ;($ III $), \mathrm{C} 6-\mathrm{N} 1-$

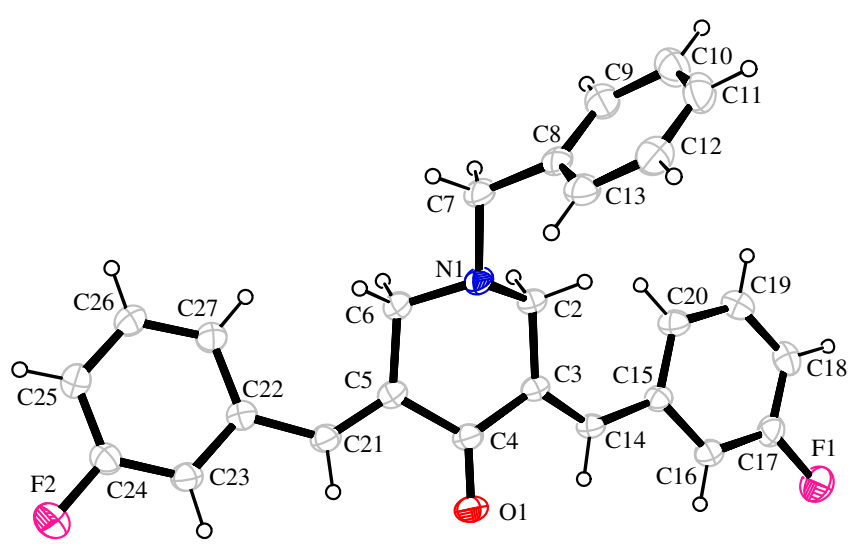

Figure 2. A view of (a) (I) with non-H atoms shown as probability ellipsoids at $30 \%$ levels. 
Table 2. Hydrogen bond and short-contact geometry in (I-III).

\begin{tabular}{|c|c|c|c|c|c|}
\hline & D-H...A & D-H $(\AA)$ & H...A $(\AA)$ & D... A $(\AA)$ & D-H...A $\left(^{\circ}\right)$ \\
\hline \multirow[t]{3}{*}{ (I) } & $\mathrm{C} 16-\mathrm{H} 16 \ldots \mathrm{O}^{\mathrm{i}}$ & 0.93 & 2.59 & $3.330(2)$ & 137 \\
\hline & C7-H7A... $\pi^{\mathrm{ii}}(\mathrm{Cg} 2)$ & 0.97 & 2.63 & $3.521(2)$ & 153 \\
\hline & $\mathrm{C} 12-\mathrm{H} 12 \ldots \pi^{\mathrm{iii}}(\mathrm{Cg} 4)$ & 0.93 & 2.83 & $3.638(2)$ & 146 \\
\hline \multirow[t]{2}{*}{ (II) } & $\mathrm{C} 10-\mathrm{H} 10 \ldots \mathrm{F} 1^{\mathrm{iv}}$ & 0.93 & 2.51 & $3.236(4)$ & 135 \\
\hline & $\mathrm{C} 21-\mathrm{H} 21 \ldots \mathrm{O} 1^{\mathrm{v}}$ & 0.93 & 2.55 & $3.400(2)$ & 152 \\
\hline \multirow[t]{3}{*}{ (III) } & $\mathrm{C} 13-\mathrm{H} 13 \ldots \mathrm{N} 1$ & 0.93 & 2.59 & $2.899(2)$ & 100 \\
\hline & $\mathrm{C} 9-\mathrm{H} 9 \ldots \pi^{\mathrm{vi}}(\mathrm{Cg} 3)$ & 0.93 & 2.82 & $3.643(3)$ & 148 \\
\hline & C28-H28B... $\pi^{\mathrm{vii}}(\mathrm{Cg} 4)$ & 0.96 & 2.95 & $3.865(3)$ & 159 \\
\hline
\end{tabular}

${ }^{\mathrm{i}} 1-\mathrm{x}, 1-\mathrm{y},-\mathrm{z} ;{ }^{\mathrm{ii}}-\mathrm{x}, 1-\mathrm{y}, 1-\mathrm{z} ;{ }^{\mathrm{iii}} 1-\mathrm{x}, 1-\mathrm{y}, 1-\mathrm{z} ;{ }^{\mathrm{iv}} 1-\mathrm{x},-\mathrm{y},-\mathrm{z} ;{ }^{\mathrm{v}} 2-\mathrm{x}, 2-\mathrm{y},-\mathrm{z} ;{ }^{\mathrm{vi}} \mathrm{x}, 1 / 2-\mathrm{y}, 1 / 2+\mathrm{z} ;{ }^{\text {vii }} 1+\mathrm{x}, \mathrm{y}, \mathrm{z} . \mathrm{Cg} 2, \mathrm{Cg} 3$ and $\mathrm{Cg} 4$ refer to the centers of $(\mathrm{C} 8-\mathrm{C} 13),(\mathrm{C} 15-\mathrm{C} 19)$ and $(\mathrm{C} 22-\mathrm{C} 27)$ rings, respectively. Significant $\pi-\pi$ interactions were observed in (III). $\mathrm{Cg} 2$ makes a stacking interaction with $\mathrm{Cg} 2^{\text {viii }}$ [symmetry code (viii): $-\mathrm{x},-\mathrm{y}, 2-\mathrm{z}$ ] with a centrioid-tocentroid distance of 4.021(2) $\mathrm{A}$, a perpendicular distance of 3.5037(7) $\mathrm{A}$, and a slippage of $1.973 \AA$.

$\mathrm{C} 7-\mathrm{C} 8=72.45(16)^{\circ}, \mathrm{N} 1-\mathrm{C} 7-\mathrm{C} 8-\mathrm{C} 13=26.4$ $(2)^{\circ}$. The intra-molecular $\mathrm{C}-\mathrm{H} \ldots \mathrm{N}$ interaction is possible when torsion angles about N1-C7 and C7C8 bonds are around $|90|^{\circ}$ and $0^{\circ}$, respectively. The intra-molecular C-H...N interaction is observed in (III), and previous analogs (3E,5E)-3,5-dibenzylidene1-phenyl-piperidin-4-one, (3E,5E)-1-Benzyl-3,5-bis(4allyloxybenzylidene)piperidin-4-one, and (3E,5E)-1benzyl-3,5-bis[(2-fluorophenyl)methylidene]piperidin4-one. ${ }^{17,18,21}$ Compounds (I-III) possess $\mathrm{C}_{\mathrm{s}}$ point group symmetry with mirror plane passing through $\mathrm{N} 1$ and C4. However, molecular symmetry is not conserved in any of the crystals. A database study suggests that the molecular symmetry is retained only in $26 \%$ of molecules possessing $\mathrm{C}_{\mathrm{s}}$ symmetry. ${ }^{22,23}$ The nonretention of molecular symmetry in the crystal could be attributed to steric reasons and packing forces, as evident from the fact that protons of 1-benzyl moiety are involved in $\mathrm{C}-\mathrm{H} . . \mathrm{F} / \mathrm{N} / \pi$ interactions (table 2 ).

\subsection{Crystal packing}

Fluorine of meta-fluorobenzylidene in (I) does not participate in any intermolecular interaction. The packing is governed by $\mathrm{C} 16-\mathrm{H} 16 . . \mathrm{O}^{\mathrm{i}}$, resulting in a dimer. Additionally, C7-H7A... $\pi^{\mathrm{ii}}(\mathrm{Cg} 2)$ and C12$\mathrm{H} 12 . . \pi^{\mathrm{iii}}(\mathrm{Cg} 4)$ interactions give rise to an adjacent dimer. Symmetry codes and ring-details are described in table 2. The crystal packing is shown in supplementary figure S3. Similarly, in ortho-F and ortho-Cl substituted analogs, namely, (3E,5E)-1-benzyl-3,5-bis (2-fluorobenzyl-idene)piperidin-4-one ${ }^{17}$ and 3,5-bis[(E)2-chlorobenzylidene]-1-[(R)-1-phenylethyl]piperidin-4-one, ${ }^{16}$ the halogen fails to participate in any non-bonded interaction scheme.

\section{$3.3 C-H . . F$ and $C-H .$. O Directed packing motif}

The notable interaction in (II) is an intermolecular $\mathrm{C} 10-\mathrm{H} 10 \ldots \mathrm{F} 1^{\text {iv }}$ interaction (table 2 ), leading to a dimer. Another dimer is formed via intermolecular C21$\mathrm{H} 21 \ldots 1^{v}$ hydrogen bond. The dimeric intermolecular $\mathrm{C}-\mathrm{H}$... O and $\mathrm{C}-\mathrm{H}$...F interactions in tandem, give rise to a linear chain (figure 3 ). The onedimensional motif is approximately parallel to [2 10 l direction.

Interestingly, the structure of (III), with ether in the para position fails to form hydrogen bond. Ether, similar to fluorine, is known to be a weak hydrogen-bonding acceptor. ${ }^{19}$ Similarly, in (3E,5E)-3,5-bis(4-ally-

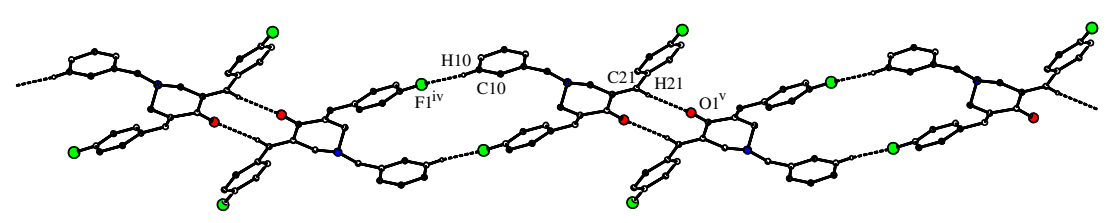

Figure 3. Packing motif (linear chain) in (II) directed by C-H...F and CH. . . O interactions. Symmetry codes are with reference to table 2. 
loxybenzylidene)-1-benzylpiperidin-4-one and 3,5-bis [(E)-4-chlorobenzylidene]-1-[(R)-1-phenylethyl]piperidin-4-one, the ether oxygen or chlorine at the paraposition does not participate in any intermolecular interaction scheme. ${ }^{18}$ Two $\mathrm{C} 9-\mathrm{H} 9 \ldots \pi^{\mathrm{vi}}(\mathrm{Cg} 3)$ and $\mathrm{C} 28-\mathrm{H} 28 \mathrm{~B} \ldots \pi^{\mathrm{vii}}(\mathrm{Cg} 4)$ interactions in (III) (table 2) make a herringbone-like arrangement as shown in the supplementary figure $\mathrm{S} 4$.

Table 3. Statistics for global (absolute) and relative competitiveness ${ }^{24}$ of fluorine for forming intermolecular interactions.

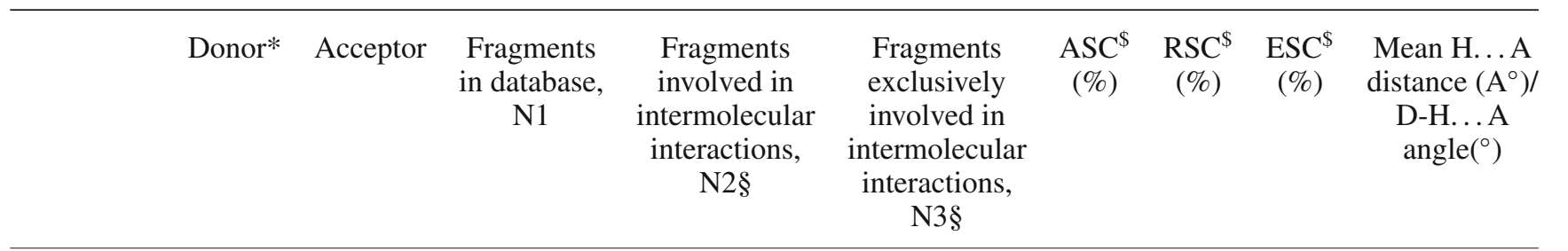

Overall competitiveness (effectiveness)

\begin{tabular}{|c|c|c|c|c|c|c|c|c|c|}
\hline \multirow[t]{4}{*}{$\mathrm{X}-\mathrm{H} . . \mathrm{F}$} & $\mathrm{C}-\mathrm{H}$ & $\mathrm{F}$ & 7789 & 4291 & - & 55 & - & - & $2.45 / 145$ \\
\hline & $\mathrm{N}-\mathrm{H}$ & $\mathrm{F}$ & 2115 & 213 & - & 10 & - & - & $2.27 / 143$ \\
\hline & $\mathrm{O}-\mathrm{H}$ & $\mathrm{F}$ & 1633 & 94 & - & 6 & - & - & $2.29 / 133$ \\
\hline & $\mathrm{Z}-\mathrm{H}$ & $\mathrm{F}$ & 7915 & 4441 & - & 56 & - & - & $2.44 / 145$ \\
\hline \multirow[t]{4}{*}{$\mathrm{X}-\mathrm{H} \ldots \mathrm{Cl}$} & $\mathrm{C}-\mathrm{H}$ & $\mathrm{Cl}$ & 14163 & 4201 & - & 30 & - & - & $2.75 / 148$ \\
\hline & $\mathrm{N}-\mathrm{H}$ & $\mathrm{Cl}$ & 3818 & 154 & - & 4 & - & - & $2.60 / 150$ \\
\hline & $\mathrm{O}-\mathrm{H}$ & $\mathrm{Cl}$ & 2966 & 98 & - & 3 & - & - & $2.59 / 139$ \\
\hline & $\mathrm{Z}-\mathrm{H}$ & $\mathrm{Cl}$ & 14215 & 4341 & - & 31 & - & - & $2.75 / 148$ \\
\hline \multirow[t]{4}{*}{$\mathrm{X}-\mathrm{H} \ldots \mathrm{Br}$} & $\mathrm{C}-\mathrm{H}$ & $\mathrm{Br}$ & 7929 & 2065 & - & 26 & - & - & $2.85 / 149$ \\
\hline & $\mathrm{N}-\mathrm{H}$ & $\mathrm{Br}$ & 1581 & 58 & - & 4 & - & - & $2.66 / 150$ \\
\hline & $\mathrm{O}-\mathrm{H}$ & $\mathrm{Br}$ & 1736 & 67 & - & 4 & - & - & $2.64 / 142$ \\
\hline & $\mathrm{Z}-\mathrm{H}$ & $\mathrm{Br}$ & 7947 & 2129 & - & 27 & - & - & $2.84 / 148$ \\
\hline \multirow[t]{4}{*}{ X-H...I } & $\mathrm{C}-\mathrm{H}$ & I & 2217 & 411 & - & 19 & - & - & $2.99 / 150$ \\
\hline & $\mathrm{N}-\mathrm{H}$ & I & 341 & 30 & - & 9 & - & - & $2.86 / 150$ \\
\hline & $\mathrm{O}-\mathrm{H}$ & I & 360 & 12 & - & 3 & - & - & $2.77 / 144$ \\
\hline & $\mathrm{Z}-\mathrm{H}$ & I & 2230 & 441 & - & 20 & - & - & $2.98 / 150$ \\
\hline \multirow[t]{3}{*}{$\mathrm{X}-\mathrm{H} \ldots \mathrm{O}$} & $\mathrm{N}-\mathrm{H}$ & $\mathrm{O}$ & 32112 & 21117 & - & 66 & - & - & $2.03 / 156$ \\
\hline & $\mathrm{O}-\mathrm{H}$ & $\mathrm{O}$ & 36714 & 23104 & - & 63 & - & - & $1.90 / 158$ \\
\hline & $\mathrm{Z}-\mathrm{H}$ & $\mathrm{O}$ & 115670 & 87491 & - & 76 & - & - & $2.29 / 151$ \\
\hline \multicolumn{10}{|c|}{ Relative competitiveness between acceptor- 1 and acceptor- 2} \\
\hline \multirow[t]{2}{*}{$\mathrm{F}$ and $\mathrm{O}$} & $\mathrm{Z}-\mathrm{H}$ & $\mathrm{F}$ & 5906 & 3156 & 671 & 53 & 42 & 11 & $2.44 / 145$ \\
\hline & & $\mathrm{O}$ & 5906 & 4231 & 1746 & 72 & 58 & 30 & $2.30 / 150$ \\
\hline \multirow[t]{2}{*}{$\mathrm{F}$ and $\mathrm{Cl}$} & $\mathrm{Z}-\mathrm{H}$ & $\mathrm{F}$ & 752 & 359 & 247 & 48 & 67 & 33 & $2.43 / 144$ \\
\hline & & $\mathrm{Cl}$ & 752 & 178 & 66 & 24 & 33 & 9 & $2.74 / 149$ \\
\hline \multirow[t]{2}{*}{$\mathrm{F}$ and $\mathrm{Br}$} & $\mathrm{Z}-\mathrm{H}$ & $\mathrm{F}$ & 311 & 165 & 128 & 53 & 74 & 41 & $2.43 / 145$ \\
\hline & & $\mathrm{Br}$ & 311 & 58 & 21 & 19 & 26 & 7 & $2.86 / 147$ \\
\hline \multirow[t]{2}{*}{$\mathrm{F}$ and $\mathrm{I}$} & $\mathrm{Z}-\mathrm{H}$ & $\mathrm{F}$ & 248 & 154 & 131 & 62 & 85 & 53 & $2.43 / 145$ \\
\hline & & I & 248 & 28 & 5 & 11 & 15 & 2 & $2.99 / 145$ \\
\hline \multirow[t]{2}{*}{$\mathrm{F}$ and $\mathrm{S}$} & $\mathrm{Z}-\mathrm{H}$ & $\mathrm{F}$ & 1640 & 817 & 676 & 50 & 78 & 41 & $2.45 / 145$ \\
\hline & & $\mathrm{S}$ & 1640 & 237 & 96 & 14 & 22 & 6 & $2.74 / 152$ \\
\hline \multirow[t]{2}{*}{$\mathrm{F}$ and $\pi$} & $\mathrm{Z}-\mathrm{H}$ & $\mathrm{F}$ & 5948 & 3476 & 1976 & 58 & 59 & 33 & $2.44 / 145$ \\
\hline & & $\pi$ & 5948 & 2396 & 896 & 40 & 41 & 15 & $2.81 / 142$ \\
\hline
\end{tabular}

$\$$ percentage figures rounded to the nearest integers, Formulae - ASC $=100 \times \frac{N 2}{N 1}$ for RSC - in a data set (containing N1 fragments) having HB groups A, B, C etc., at first their ASC values are calculated $[$ ASC $(A)=N 2(A) / N 1, A S C(B)=N 2(B) / N 1$ and so on, where N2(A), N2(B) ... are the numbers of hydrogen bonding refcodes for HB groups A, B ... respectively. RSC is then expressed as RSC (i) $=100 \times \frac{A S C(i)}{\sum_{\mathrm{i}} \mathrm{ASC}(\mathrm{i})}, \mathrm{ESC}(\mathrm{i})=100 \times \frac{N 3(i)}{N 1}$, where $\mathrm{i}=\mathrm{HB}$ groups namely, A, B, C etc., N3(i) represents cases when HB group (i) forms hydrogen bond and rest of the groups (under consideration) fail to form it. * Z refers to any atom other than $\mathrm{H}$.

${ }^{\S}$ In RSC figures: the N2 (Column 4th) refers to cases wherein Acceptor-1 was found hydrogen bonded and it does not matter if competing Acceptor-2 is hydrogen bonded or not. In ESC figures: The N3 (Column 5th) refers to fragments where Acceptor-1 is hydrogen bonded and Acceptor-2 does not participate in any kind of hydrogen bonding 


\subsection{High occurrence of $\mathrm{C}-\mathrm{H}$...F interactions in organic molecules}

The ability of hydrogen bonding donors and acceptors (hereafter referred to as HB groups) to form interactions and direct packing in the presence of multiple such groups is determined by many factors. ${ }^{20,31} \mathrm{We}$ call the ability of an HB group to form interactions as effectiveness (or competitiveness). To quantify this effectiveness of HB groups, we have recently formulated a new concept of statistical competitiveness, defined in terms of three numerical parameters, referred to as ASC (absolute statistical competitiveness), RSC (relative statistical competitiveness) and ESC (exclusive statistical competitiveness) (see table 3 for the definition of parameters). ${ }^{24}$ ASC indicates the global effectiveness (or propensity) of an HB group to form interactions. The RSC and ESC signify the probability of an HB group to form hydrogen bond in a co-existing situation. ESC, unlike RSC suggests the ability to form interactions exclusively. Few attempts in this direction were earlier also made, to rank the effectiveness of HB groups and the quantities were referred by various names such as probabilities, relative success, propensity or competition function. ${ }^{25-30}$

To investigate the efficacy of fluorine for making interactions, these parameters were calculated using Cambridge Structural Database (CSD) (Version 5.31). ${ }^{15}$ All intra-molecular short-contacts were excluded. The results are summarized in table 3 . An interesting fact that emerges from the study is the predominant global effectiveness of $\mathrm{C}-\mathrm{H}$...F interactions in organic crystals. An overwhelming 55\% of cases are reported to have $\mathrm{C}-\mathrm{H}$. . . F interactions $(56 \%$ for Z$\mathrm{H}$...F interactions, $\mathrm{Z}$ represents any atom other than $\mathrm{H})$. The propensity of $\mathrm{C}-\mathrm{H}$...F intermolecular interactions is at par with some of the common intermolecular interactions. The ASC values for $\mathrm{N}-\mathrm{H}$... O, O$\mathrm{H} . \ldots \mathrm{O}$ and $\mathrm{Z}-\mathrm{H} . \ldots \mathrm{O}$ interactions are $66 \%, 63 \%$ and $76 \%$, respectively. On the other hand, the ASC value for intermolecular $\mathrm{N}-\mathrm{H}$...F and $\mathrm{O}-\mathrm{H}$...F interactions are barely $10 \%$ and $6 \%$, respectively. The 'odd' behaviour of fluorine, attributed in previous database studies ${ }^{2}$ is largely due to its low propensity (effectiveness) of forming interactions with these strong $\mathrm{NH} / \mathrm{OH}$ donors. The present statistics reveals considerable role of weak interactions involving fluorine in a large number of reported examples.

We also compared relative competitiveness of fluorine with respect to other acceptors. The RSC and ESC parameters suggest that fluorine, when in competition with oxygen acceptors, retains significant abil- ity to form H...F intermolecular interactions. It is also interesting to note that there are still $11 \%$ cases, when it is able to form exclusive interactions. Fluorine has high competitiveness with respect to other weak (such as $\pi$ ) acceptors. It would be worthwhile to compare the effectiveness of fluorine with respect to other halogens (for $\mathrm{C}-\mathrm{H}$... halogen interactions see ${ }^{31-33}$ ). In comparison to other halogens, fluorine has the highest effectiveness (as expected) with all the three statistical parameters are higher for fluorine in all the cases. The order of effectiveness for halogen is as follows $\mathrm{F}>\mathrm{Cl}>\mathrm{Br}>\mathrm{I}$.

\section{Conclusion}

Three dibenzylidene-4-piperidones derivatives were synthesized and structures examined. In parafluorosubstituted dibenzylidene compound, fluorine participates in $\mathrm{C}-\mathrm{H}$...F interaction, leading to a onedimensional packing motif. Rest of the investigated compounds are governed by $\mathrm{C}-\mathrm{H} \ldots \mathrm{O}$ and $\mathrm{C}-\mathrm{H} . \ldots \pi$ interactions. The database analysis suggests significant role of fluorine-mediated intermolecular interactions. Based on three statistical descriptors that quantify the effectiveness of HB groups to form intermolecular interactions, it turns out that the global effectiveness (or propensity) for intermolecular $\mathrm{C}-\mathrm{H}$...F interaction is substantially higher, which is comparable to conventional strong intermolecular $\mathrm{N}-\mathrm{H}$... O and $\mathrm{O}-$ $\mathrm{H}$... O hydrogen bonds. Moreover, fluorine possesses significant ability to form exclusive intermolecular interactions as well, when in competition with oxygen acceptor.

As illustrated in the present examples, and revealed in the database study, the intermolecular interactions involving fluorine are even though weak, but do have significant ability to direct the molecular packing, suggesting much larger role of fluorine in crystal packing than considered in earlier studies. The frequently associated term 'hardly ever accepts hydrogen bond' is gradually being replaced by 'it can also play structure directing role'. The present investigation adds to this theoretical framework.

\section{Supplementary information}

For supplementary information figures S1, S2, S3 and S4 see www.ias.ac.in/chemsci website.

\section{Acknowledgements}

RSR thanks Council of Scientific and Industrial Research, New Delhi, for funding under the scientist's 
pool scheme, and Bioinformatics Infrastructure Facility of the University of Hyderabad for computational resources. Authors also thank Mr. V Ramkumar, Department of Chemistry, Indian Institute of Technology (IIT) Madras, for help in XRD experiment.

\section{References}

1. Dunitz J D 2004 Chem. BioChem. 5614

2. Dunitz J D and Taylor R 1997 Chem. Eur. J. 389

3. Howard J A K, Hoy V J, O' Hagan, D and Smith G T 1996 Tetrahedron 5212613

4. Zhu Y-Y, Wu J, Li C, Zhu J, Hou J-L, Li C-Z, Jiang X-K and Li Z-T 2007 Cryst. Growth Des. 71491

5. Shimoni L and Glusker J P 1994 Struct.Chem. 5 383

6. Choudhury A R, Urs U K, Guru Row T N and Nagarajan K 2002 J. Mol. Struct. $\mathbf{6 0 5} 71$

7. Prasanna M D and Guru Row T N 2000 Cryst. Eng. Commun. 225

8. Choudhury A R, Guru Row T N 2004 Cryst. Growth Des. 447

9. Choudhury A R and Guru Row T N 2006 Cryst. Eng. Commun. 8265

10. Chopra D, Nagarajan K and Guru Row T N 2008 J. Mol. Struct. $\mathbf{8 8 8} 70$

11. Müller K, Faeh C and Diederich F 2007 Science 317 1881

12. Restorp P, Berryman O B, Sather A C, Ajami D and Rebek J Jr 2009 Chem. Commun. 5692

13. Bruker 2004 APEXII (version 1.08), SAINT-Plus (version 7.23A) and SADABS (version 2004/1). Bruker AXS Inc., Madison, Wisconsin, USA

14. Sheldrick G M 2008 Acta Crystallogr. Section A 64 112

15. Allen F H 2002 Acta Crystallogr. Section B 58380

16. Suresh J, Suresh Kumar R, Perumal S and Natarajan S 2007 Acta Crystallogr. Section C 630315
17. Rathore R S, Karthikeyan N S, Sathiyanarayanan K and Aravindan P G 2009 Acta Crystallogr. Section E 65 02667

18. Karthikeyan N S, Sathiyanarayanan K, Aravindan P G and Rathore R S 2009a Acta Crystallogr. Section E 65 02775

19. Lommerse J P M, Price S L and Taylor R 1997 J. Comput. Chem. 18757

20. Desiraju G R 2002 Acc. Chem. Res. 35565

21. Karthikeyan N S, Sathiyanarayanan K, Aravindan P G, Ghosh H and Rathore R S 2009b Acta Crystallogr. Section E 6503062

22. Pidcock E, Motherwell W D S and Cole J C 2003 Acta Crystallogr. Section B 59634

23. Narasegowda R S, Malathy Sony S M, Mondal S, Nagaraj B, Yathirajan H S, Narasimhamurthy T, Charles P, Ponnuswamy M N, Nethaji M and Rathore R S 2005 Acta Crystallogr. Section E $\mathbf{6 1}$ 0843; references therein

24. Rathore R S, Alekhya Y, Kondapi A K and Sathiyanarayanan K 2011 Cryst. Eng. Comm. x, in press, doi:10.1039/c1ce05034f.

25. Allen F H, Motherwell W D S, Raithby P R, Shields G $\mathrm{P}$ and Taylor R 1999 New J. Chem. 2325

26. Steiner T 2001 Acta Crystallogr. Section B 57103

27. Ziao N, me Graton J, Laurence C and Le Questel J-Y 2001 Acta Crystallogr. Section B 57850

28. Ziao N, Laurence C and Le Questel J-Y 2002 Cryst. Eng. Commun. 4326

29. Galek P T A, Fábián L, Motherwell W D S, Allen F H and Feeder N 2007 Acta Crystallogr. Section B 63768

30. Galek P T A, Allen F H, Fábián L and Feeder N 2009 Cryst. Eng. Commun. 112634

31. Desiraju G R and Steiner T 1999 The weak hydrogen bond in structural chemistry and biology. (New York: Oxford University Press), Section 3.2.1; references therein

32. Rathore R S, Narasimhamurthy T, Vijay T, Yathirajan H S and Nagaraja P 2006 Acta Crystallogr. Section C 62 036

33. Hathwar V R, Roopan S M, Subashini R, Nawaz Khan F and Guru Row T N 2010 J. Chem. Sci. 122677 